\title{
POSISI PERDAGANGAN KARET INDONESIA DALAM MENGHADAPI PASAR GLOBAL
}

(Studi Kasus Ekspor Impor Karet Indonesia Tahun 2014-2018)

\author{
Sang Saniaka Tajulfitri \\ Widyaiswara Ahli Madya \\ Pusdiklat Perdagangan
}

\begin{abstract}
Rubber is one of Indonesia's largest commodities after palm oil, and $85 \%$ of its production is carried out by small farmers. This plant has strategic value and is a plant that contributes to foreign exchange for the nation. At present Indonesia's Trade Specialization Index (ISP) is a rubber exporting country, based on the calculation of the average ISP for the 2014-2018 period, with the value of Indonesian ISPS at 0.54. This shows that Indonesian rubber commodities are in the maturation stage in world trade or have very strong competitiveness.
\end{abstract}

Keywords: Index of Specialization in Trade, Rubber, Competitiveness

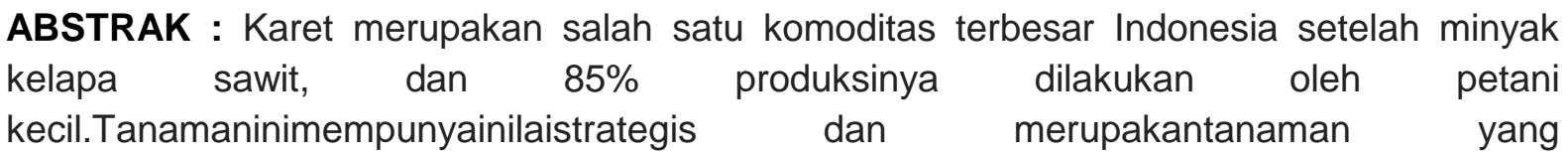
memberikansumbangandevisabaginasional. SaatiniNilai Indeks Spesialisasi Perdagangan (ISP) Indonesia menjadi negara pengekspor karet, berdasarkan perhitungan rata-rata ISP periodetahun 2014-2018, dengannilai ISP Indonesia sebesar 0.54. Hal ini menunjukkan bahwa komoditas karet Indonesia berada dalam tahap pematangan dalam perdagangan dunia atau memiliki daya saing yang sangat kuat.

Kata kunci :Indek Spesialisasi Perdagangan, Karet, Daya saing

\section{PENDAHULUAN}

Dunia mengenal Indonesia memiliki kekayaan alam yang melimpah seperti karet, kopi, cengkeh, dan lain-lain. Perkebunan merupakan salah satu sektor penyumbang ekspor Indonesia dan subsektor perkebunan merupakan subsektor potensial yang ikut berperan dalam meningkatkan nilai ekspor komoditas perkebunandi Indonesia. Salah satu komoditas potensial pada sektor perkebunan yang memiliki potensi pasar yang cukup luas, terutama di pasar dunia adalah karet. Salah satu produksi karet dunia selain Indonesia diproduksi oleh Malaysia dan Thailand. Ketiga negara tersebut tergabung dalam komunitas produsen karet dunia atau International
Rubber Council (IRC).Objek tulisan ini adalah spesialisasi perdagangan komoditas karet Indonesia pada tahun 2014-2018. Data yang digunakan diperoleh dari berita media cetak. Tujuan dari penulisan ini adalah untuk mengetahui posisi Indonesia apakah sebagai salah satu negara eksportir atau importir utama karet dunia saat ini.

\section{TINJAUAN PUSTAKA \\ Perdagangan Internasional}

Perdagangan internasional tidak sesederhana sebagaimana perdagangan dalam negeri, karena negara dihadapkan dengan batasan-batasan yang menghambat perdagangan seperti bea, tarif dan kuota barang impor. Dalam 
perdagangan internasional negara-negara dapat membuat perjanjian atau kerja sama antar negara yang bertujuan untuk memperluas pasar perdagangan dan membuatnya lebih luas dibandingkan dengan negara lain

\section{Daya Saing}

$\begin{array}{ccc}\text { Suatu } & \text { negara dapat dikatakan } \\ \text { berhasil } & \text { dalam } & \text { perdagangan }\end{array}$
internasionalnya dapat dilihat dari daya saingnya. Daya saing merupakan konsep umum yang digunakan untuk merujuk pada komitmen persaingan pasar terhadap keberhasilan suatu negara dalam persaingan internasional dan memiliki peranan penting dalam meningkatkan daya saing dengan membuat kebijakan win-win solution baik ekonomi ataupun politik.

\section{Indeks Spesialisasi Perdagangan (ISP)}

Indeks Spesialisasi Perdagangan (ISP) merupakan indeks yang digunakan untuk menghitung spesialisasi perdagangan suatu negara. ISP menganalisis posisi atau tahapan perkembangan suatu komoditas dengan menggambarkan apakah untuk suatu komoditas, posisi Indonesia cenderung menjadi negara eksportir atau importir (kemendag.go.id). ISP merupakan perbandingan antara selisih nilai bersih perdagangan dengan nilai total perdagangan dari suatu negara. Indeks Spesialisasi Perdagangan (ISP) digunakan untuk menganalisis posisi atau tahapan perkembangan suatu produk (kemendag.go.id).Nilai indeks ini adalah antara 0 dan 1. Jika nilai positif (diatas 0 sampai dengan 1), maka komoditi tersebut memiliki daya saing yang tinggi atau negara/wilayah bersangkutan cenderung sebagai negara pengekspor dari komoditi

\section{Teknik Analisis Data}

tersebut. Sebaliknya, jika nilainya negatif (dibawah 0 hingga -1) daya saing rendah atau cenderung sebagai pengimpor (kemendag.go.id).

\section{METODE PENELITIAN}

\section{Jenis Penelitian}

Tulisan ini menggunakan metode penelitian kuantitatif deskriptif yang dilakukan untuk memberikan gambaran mengenai suatu gejala atau fenomena dan hasil dari kajian ini yang kemudian diolah dan dianalisis untuk diambil kesimpulannya.

\section{Objek Penelitian}

Objek penulisan adalah spesialisasi perdagangan komoditas karet Indonesia pada tahun 2014-2018.

\section{Variabel Penelitian}

Variabel dalam penulisan ini adalah: Spesialisasi Perdagangan Karet Indonesia . Perhitungan spesialisasi perdagangan dalam tulisan ini menggunakan nilai ekspor karet Indonesia tahun 2014 hingga 2018. Indeks Spesialisasi Perdagangan (ISP) digunakan untuk mengukur spesialisasi perdagangan karet Indonesia dan mengetahui posisi indonesia sebagai negara pengekspor atau pengimpor komoditi karet dunia.

\section{Teknik Pengumpulan Data dan Jenis Data}

Dalam penulisan ini penulis menggunakan teknik pengumpulan data dokumentasi pada lembaga seperti Badan Pusat Statistik (BPS), Kementrian Perdagangan, dan media massa.

Metode analisis yang digunakan dalam penulisan ini adalah dengan 
metode kuantitatif deskriptif, yakni dengan

1. Melakukan pengukuran dengan menggunakan rumus sebagai berikut :

Indeks Spesialisasi Perdagangan (ISP)

$: \mathrm{ISP}=(\mathrm{Xla}-\mathrm{Mla}) /(\mathrm{Xla}+\mathrm{Mla})$

\section{HASIL DAN PEMBAHASAN}

\section{Gambaran Umum Karet}

Karet merupakan salah satu komoditas penting dan terbesar Indonesia setelah minyak kelapa sawit, dan 85\% produksinya dilakukan oleh petani kecil. Karet terdiri dari polimer senyawa organic isoprena, senyawa organic lainnya dan air. Kebanyakan karet komersial berasal dari getah pohon para karet (para rubber tree) atau Heveabrasiliensis. Sebagai salah satu produsen karet terbesar di dunia, jumlah suplai karet Indonesia penting untuk pasar global. Sejak tahun 1980an, industri karet Indonesia telah mengalami pertumbuhan produksi yang stabil. Kebanyakan hasil produksi karet negara ini - kira-kira 80\% - diproduksi oleh para petani kecil. Oleh karena itu, perkebunan Pemerintah dan swasta memiliki peran yang kecil dalam industry karet domestik. Kebanyakan produksi karet Indonesia berasal dari provinsiprovinsi berikut : Sumatra Selatan, Sumatra Utara, Riau, Jambi dan Kalimantan Barat.

Total luas perkebunan karet Indonesia telah meningkat secara stabil selama satu decade terakhir. Di tahun 2016, perkebunan karet di negara ini mencapai luas total 3,64juta hektar (https://www.gapkindo.org/images/statistic s/1.1.-LUAS-DAN-PRODUKSI-KEBUNKARET-INDONESIA-20122018.jpg).Jumlah perkebunan karetmilik
2. Menganalisis dan menginterptretasikan hasil tulisan dan membahas dari setiap

3. Pengukuran berdasarkan analisis yang dilakukan dengan rumus ISP.

petani kecil/rakyat sebesar 15.239 juta hektar, sementara perkebunan Swasta sebesar 1.492 juta hektar swasta sebesar 1.192 juta hektar (https://www.gapkindo.org/images/statistic s/1.1.-LUAS-DAN-PRODUKSI-KEBUNKARET-INDONESIA-2012-2018.jpg). Indonesia mempunyai potensi ekspor karet yang baik dimana terdapat lima negara tujuan ekspor karet Indonesia yaitu Amerika Serikat dengannilai 5,172 juta US\$ disusul Jepang, Tiongkok, India, dan Korea Selatan yaitu dengan masingmasing nilai sebesar 3,683 juta US\$, 3.464 juta US\$, 1.605 juta US\$ dan 1.478 juta US\$ (BPS).

\section{Pangsa Industri Karet}

Potensi indutsri karet sangat tinggi untuk dikembangkan.Jika dibandingkan dengan negara tetangga Malaysia, Indonesia mempunyai potensi besar. Tercatat pangsa relative karet Malaysia pada tahun 2010 hanya sebesar 10,6 persen jauh lebih kecil dibandingkan dengan Indonesia yang mencapai 27,4 persen. Demikian halnya dengan negara Asean lainnya yaitu Vietnam hanya mempunyai pangsa relative 8,1 persen (Gambar 1). Saat ini sebanyak 6.125 desa di seluruh wilayah Indonesia telah mengusahakan komoditi karet tersebut selain dua komoditas utama lainnya seperti padi dan palawija dengan jumlah desa adalah 31.213 desa dan 13.893 desa. 


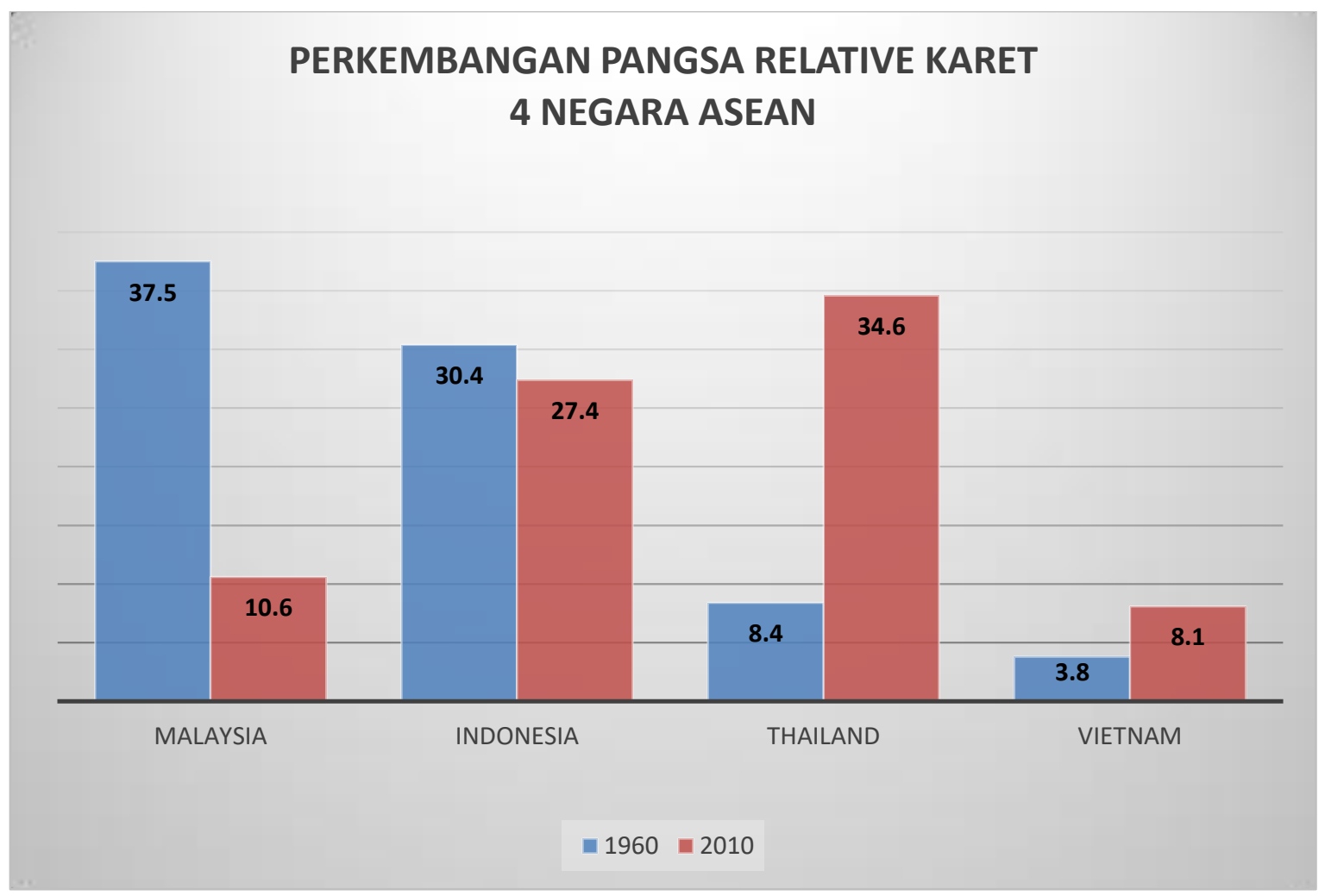

Gambar 1. Pangsa Relative Karet (\%)

\begin{abstract}
Tantangan yang dihadapi Indonesia dalam menghadapi pangsa relative negara Thailand cukup tinggi, dikarenakan pangsa relative Thailand sebesar 34.6 persen masih jauh lebih tinggi dibandingkan dengan pangsa relative Indonesia yang hanya mencapai 27,4 persen. Industri alas kaki nasional (Gambar 2) semakin lama mendapat tantangan dari negara pesaing lainnya. Industri karet masih menjadi prioritas nasional ketiga dibandingkan industri beras dan palawija. Penguatan struktur industri karet, peningkatan akses pasar produk hilir, penciptaan iklim usaha yang kondusif, serta penguasaan teknologi dan pengembangan penelitian menjadi hal penting yang perlu diperhatikan oleh pihak Pemerintah dan Swasta.
\end{abstract}

\section{Pohon Industri Karet}

Terlihat bahwa komoditas karet ini mempunyai 2 turunan primer utama antara lain Getah karet dan Biji karet dan selanjutnya menjadi turunan sekunder yaitu latex menjadi turunan selanjutnya alat kesehatan dan laboratorium menjadi pipet, sarung tangan dan kondom serta cat dan crumb rubber menjadi ban, perlengkapan kedaraan lain, perlengkapan pakaian olah raga, teknik industry, anak dan bayi,barang lain serta biji karet menjadi minyak, tempurung, bungkil dan menjadi turunan terakhir adalah pedal sepeda, sepatu, sandal, balon, dot botol susu, karpet/keset mebel, pelampung, bangunan tahan gempa dan ban vulkanisir (Gambar 2) berikut ini : 


\section{POHON INDUSTRI KARET}

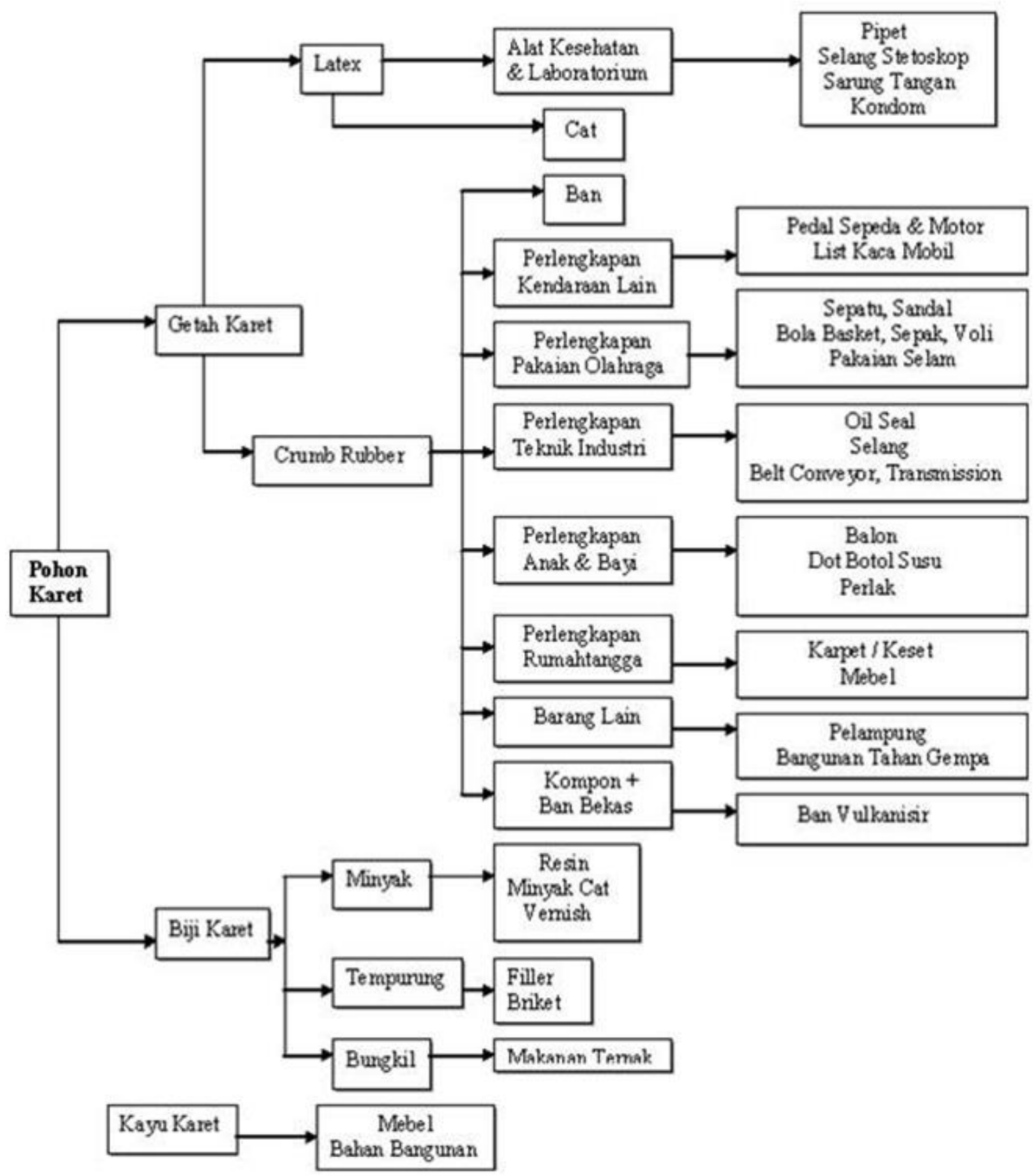

https://anagotik.blogspot.com/2015/03/pohon-industri-karet.html

Gambar 2. Pohon Industri Karet

\section{Perkembangan Nilai Ekspor dan Impor Karet}

Nilai Ekspor karet Indonesia pada tahun 2014 tercatat sebesar 7,10 miliar US\$ dan mengalami penurunan sampai dengan tahun 2015-2016 menjadi 5.91 milyar US\$ dan 5,66 milyar US\$ dan kembali meningkat pada tahun 2017 menjadi 7,74 miliar US\$. Namun nilai ekspor kembali mengalami penurunan 
pada tahun 2018 menjadi 6,38 miliar US\$.Trend ekspor karet nasional selama lima tahun hanya sebesar 0.56 persen, jauh lebih kecil dibandingkan dengan trend impor karet nasional. Jumlah ekspor karet selama periode 2014-2018 mencapai 32.79 milyar US\$. Nilai ekspor dan neraca perdagangan komoditi karet selama periode 2017-2018 sama-sama mengalami penurunan masing-masing sebesar $-17,57$ dan $-28,80$ persen. Ratarata nilai ekspor karet nasional tercatat sebesar 6,558 milyar US\$ masih jauh lebih besar dibandingkan dengan rata-rata nilai impor karet. Lalu bagaimana dengan perkembangan nilai impor karet?

Ternyata dibandingkan dengan nilai ekspor karet, maka nilai impor karet
Indonesia masih jauh lebih kecil dibandingkan dengan nilai ekspornya. Nilai impor karet pada tahun 2018 adalah yang terbesar dibandingkan dengan nilai impor tahun-tahun sebelumnya yaitu tahun 2014 sebesar 2,01 milyar US\$ kemudian tahun 2015 sebesar 1,68 milyar US\$ 1,70 milyar US\$ dan meningkat kembali pada tahun 2017 dengan nilaisebesar 2,08 miliar US\$ dan terakhir tahun 2018 menjadi 2,35 milyar US\$ (Gambar 3). Nilai impor karet mengalami kenaikan pada dua tahun terakhir 20172018 sebesar 12,98 persen lebih tinggi dibandingkan perubahan nilai ekspor karet pada periode yang sama.

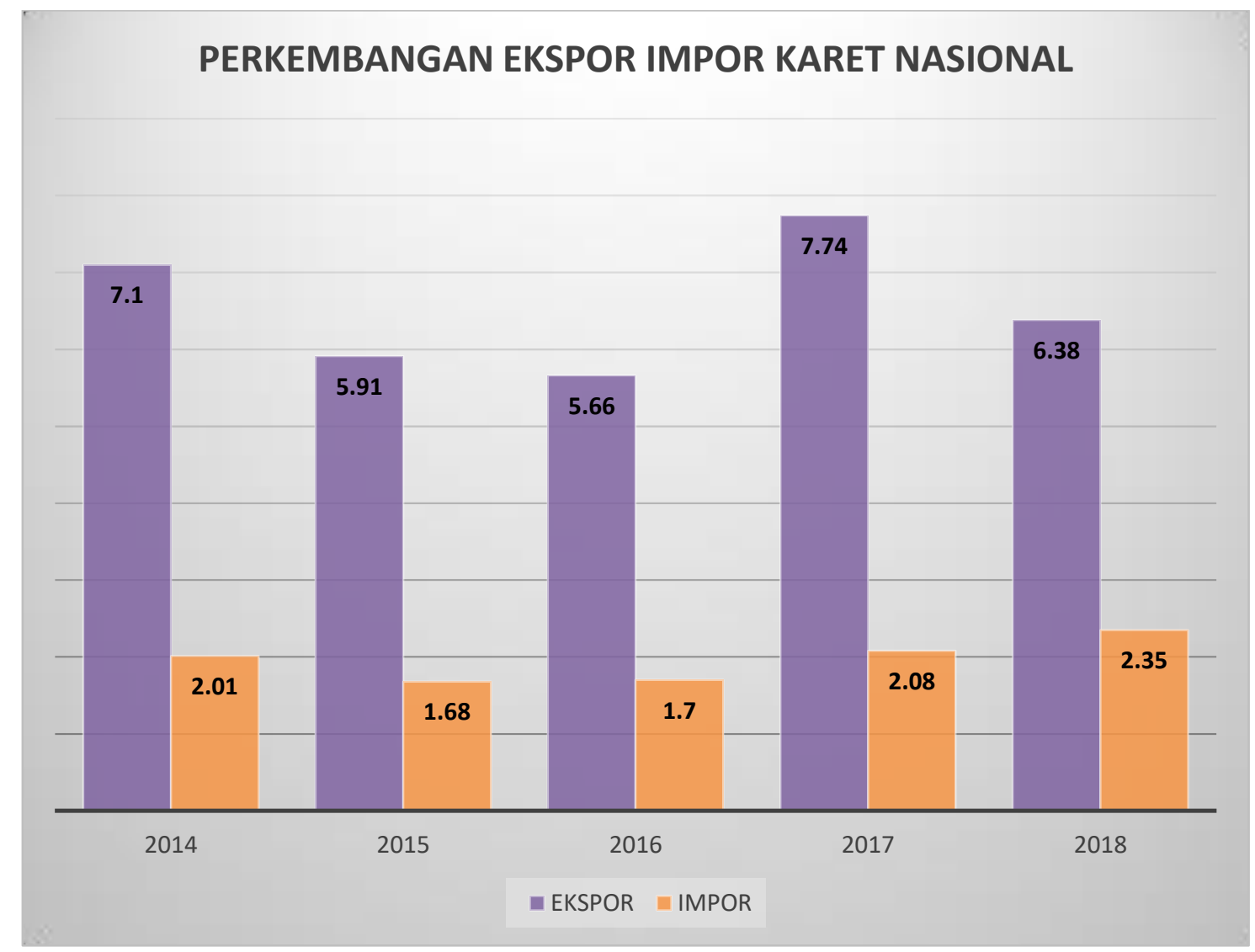

Gambar 3. Ekspor Impor Karet Nasional 


\section{Hasil Analisis ISP Komoditas Karet}

Hasil perhitungan menunjukkan bahwa Indonesia mempunyai nilai Indeks Spesialisasi Perdagangan (ISP) rata-rata sebesar 0.54. Nilai ISP tertinggi terjadi pada tahun 2017 yaitu 0.58 dan kemudian kembali menurun pada tahun 2018 sebesar 0.46. Dengan gambaran tersebut terlihat bahwa komoditi karet nasional, termasuk dalam golongan produk yang memiliki daya saing yang sangat kuat dan termasuk dalam golongan produk yang sudah dalam tahap kematangan (Gambar 4) dibawah ini :

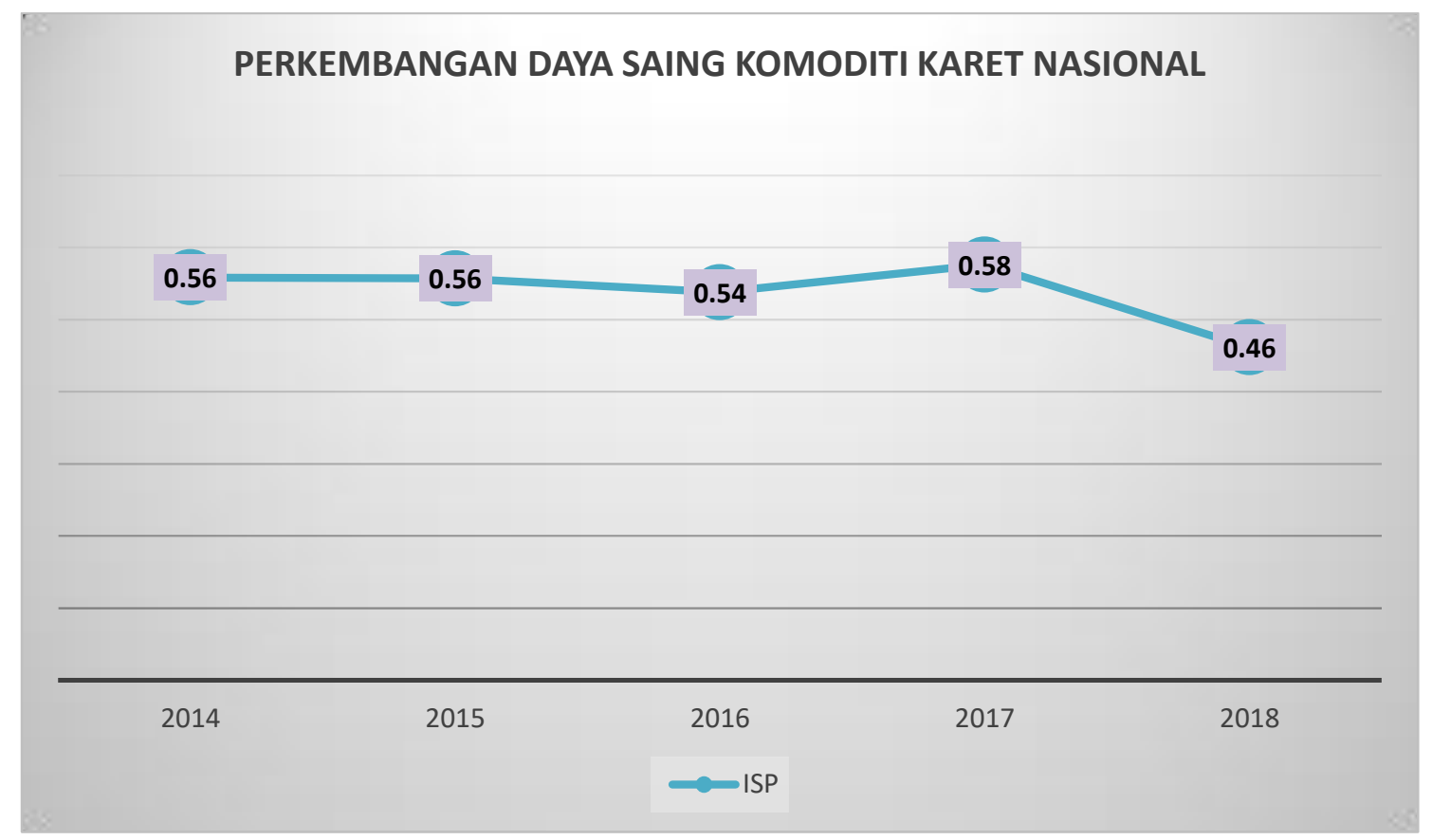

Gambar 4. Nilai ISP Karet Nasional

\section{KESIMPULAN DAN SARAN}

\section{Kesimpulan}

Dari hasil pembahasan dengan menggunakan metode ISP maka dapat ditarik kesimpulan bahwa Indonesia masih menjadi salah satu negara pengekspor karet utama dunia dimana perhitungan rata-rata ISP tahun 2014-2018, adalah sebesar 0.54 diatas nilai 0 . Hal ini menunjukkan bahwa komoditas karet Indonesia berada dalam tahap pematangan dalam perdagangan dunia atau Indonesia memiliki daya saing yang sangat kuat pada komoditi karet tersebut .

\section{Saran}

Adapun saran yang dapat disampaikan dalam tulisan ini adalah pengembangan industri hulu dan hilir dapat terus dilanjutkan dan menjadi penting untuk dilakukan mengingat karet merupakan komoditas utama terbanyak ketiga yang diusahakan pada 6.125 desa di seluruh wilayah Indonesia dan merupakan salah satu andalan ekspor komoditi nasional. 
Selain itu peraturan yang mampu meningkatkan potensi karet dalam negeri khususnya terkait dengan perbaikan iklim usaha dalam kemudahan berinvestasi menjadi perhatian utama kedepan sehingga memunculkan ketertarikan untuk terus meningkatkan produksi karet agar produktivitas karet dalam negeri serta daya saing industry karet terus meningkat.

\section{DAFTAR PUSTAKA}

www.kemendag.go.id/addon/isp/index.php

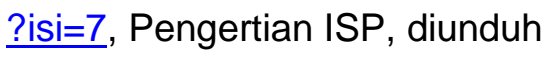
tanggal 17 April 2019

https://id.wikipedia.org/wiki/Karet, diunduh tanggal 21 April 2019

https://www.gapkindo.org/images/statistics 11.1.-luas-dan-produksi-kebunkaret-indonesia-2012-2018.jpg, diunduh tanggal 5 Mei 2019

https://www.bps.go.id/subject/8/eksporimpor.html, diunduh tanggal 25 Mei 2019

https://anagotik.blogspot.com/2015/03/poh on-industri-karet.html, diunduh tanggal 30 Mei 2019

https://koran.bisnis.com/read/20190527/43 0/927513/pengembangan-industri2-kek-layak-jadi-sentra-karet, diunduh tanggal 11 Juni 2019

https://koran.tempo.co/read/443452/invest asi-kerja-sama-desa-dan-swasta-capai-rp60-triliun, diunduh tanggal 27 Juni 2019. 